\title{
Severe oropharyngeal trauma caused by toothbrush - case report and review of 13 cases
}

\author{
S. Kumar, ${ }^{1}$ R. Gupta, ${ }^{2}$ R. Arora ${ }^{3}$ and S. Saxena ${ }^{4}$
}
IN BRIEF
- Dental practitioners may be the first specialists to be consulted for intra-oral injuries caused by a toothbrush.
- Although uncommon, they need to be evaluated very carefully because of their potential to become life-threatening.
- Expert opinion should be sought in cases of neurological involvement or infection.
- Parents/carers of toddlers/epileptics need to be educated on the importance of supervised oral health care.

\section{VERIFIABLE CPD PAPER}

Foreign body trauma to the oral cavity is fairly common. However, severe injuries caused by a toothbrush are rarely reported. We report a case of a 35-year-old epileptic patient who suffered seizures while brushing his teeth. During this episode, he self-inflicted a grievous injury to his oro-pharynx with his toothbrush which went unnoticed for 11 months. Thirteen cases of toothbrush induced trauma to this area are reviewed and a classification of these injuries is proposed. Complications related to these injuries are highlighted and their management discussed.

\section{INTRODUCTION}

A manual toothbrush is an essential everyday tool for maintaining oral hygiene and is rarely considered to be a device capable of causing injury. Yet Hefflin et al. estimated that 2,489 toothbrush mishaps classified as 'oral laceration resulting from accident while using device' occurred in the US between July 1999 and June 2000. ${ }^{1}$ Generally such injuries are minor and require little by way of management.

Occasionally, however, severe injuries may be caused when enough force is generated to drive the toothbrush into the soft tissues: usually in toddlers who fall with a toothbrush in their mouth.

These injuries may occur lateral to the ramus of the mandible into the cheek causing deep laceration, herniation of the buccal fat pad or impalement of the toothbrush. ${ }^{2}$ Nevertheless, such injuries are relatively less dangerous and easy to manage since they do not involve any major neurovascular structures.

On the other hand, extreme vigilance is required when trauma is sustained

\footnotetext{
${ }^{1 ;}, 4$ Oral and Maxillofacial Surgery, Subharti Dental College, Meerut, India; ${ }^{2,3}$ Maharaja Agrasen Hospital, Delhi, India

${ }^{*}$ Correspondence to: Dr Sanjeev Kumar

Email: saxroy@yahoo.com
}

\section{Refereed Paper}

Accepted 11 July 2008

DOI: $10.1038 /$ sj.bdj.2008.893

${ }^{\bullet}$ British Dental Journal 2008; 205: 443-447

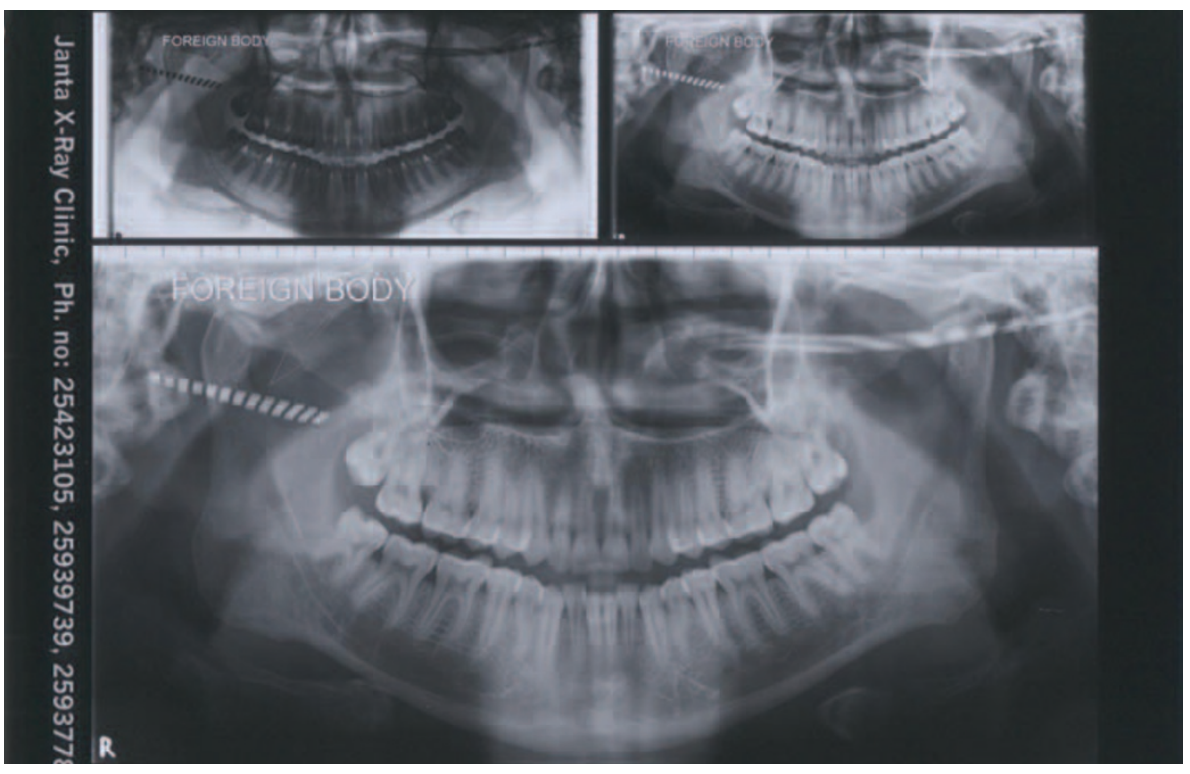

Fig. 1 OPG shows presence of foreign body at the level of the sigmoid notch

to the soft palate, tonsillar fauces or oropharynx, as even seemingly trivial injuries have the potential to become life-threatening.

We review the literature with regard to oropharyngeal trauma (OPT) caused by a toothbrush and discuss the sequelae of such injuries. An unusual case of the head of a toothbrush embedded in the pterygomandibular space for 11 months is also presented.

\section{CASE REPORT}

A 35-year-old male patient reported to the dental department seeking treatment for long standing trismus and pus discharge from the oral cavity. The history revealed that he was a poorly controlled epileptic who had an attack of seizures while brushing his teeth 11 months earlier at his village in remote Rajasthan. He remembered having sustained a laceration in the right retromolar trigone during the episode which healed uneventfully. No attention was paid to the toothbrush at the time. A month later he gradually started developing trismus and a purulent discharge from his mouth. He had consumed several courses of antibiotics during the subsequent period, none of which gave him lasting relief. On examination, the patient had a mild swelling over the right submandibular area and had complete trismus. 


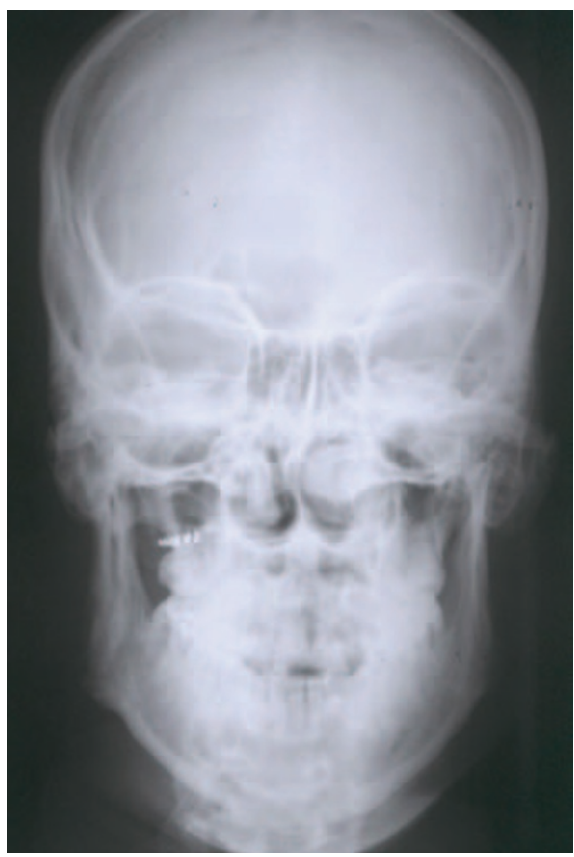

Fig. 2 PA Skull reveals the foreign body medial to the ramus

Halitosis was marked and purulent discharge could be seen oozing from the distal to the right lower third molar. A complete intra-oral examination was not possible because of limited mouth opening. OPG revealed an unusual radiopaque shadow in the mid-ramus area which suggested the presence of a foreign body (Fig. 1). A PA skull showed this foreign body to be medial to the ramus of the mandible (Fig. 2). A subsequent CT scan revealed the definite outline of the head of a toothbrush embedded in the pterygomandibular space (Fig. 3). The facility for 3D reconstruction was not available at the centre. The patient was prepared for surgery under GA and under fibro-optic assisted nasal intubation, the sinus distal to the lower right third molar was explored. The embedded head of the toothbrush was felt as a hard mass which was then bluntly dissected out leading to a gush of pus from the cavity (Fig. 4). The wound was then irrigated with Povidone Iodine solution and packed with a ribbon gauze to maintain patency. The patient was put on intravenous Augmentin $1.2 \mathrm{~g}$ and metronidazole $500 \mathrm{mg}$ T. I. D for a week post-operatively. A Ferguson's mouth gag was used to achieve $35 \mathrm{~mm}$ of mouth opening. Regular dressings were carried out and the patient discharged after ten days. At the time of discharge there was no pus drainage

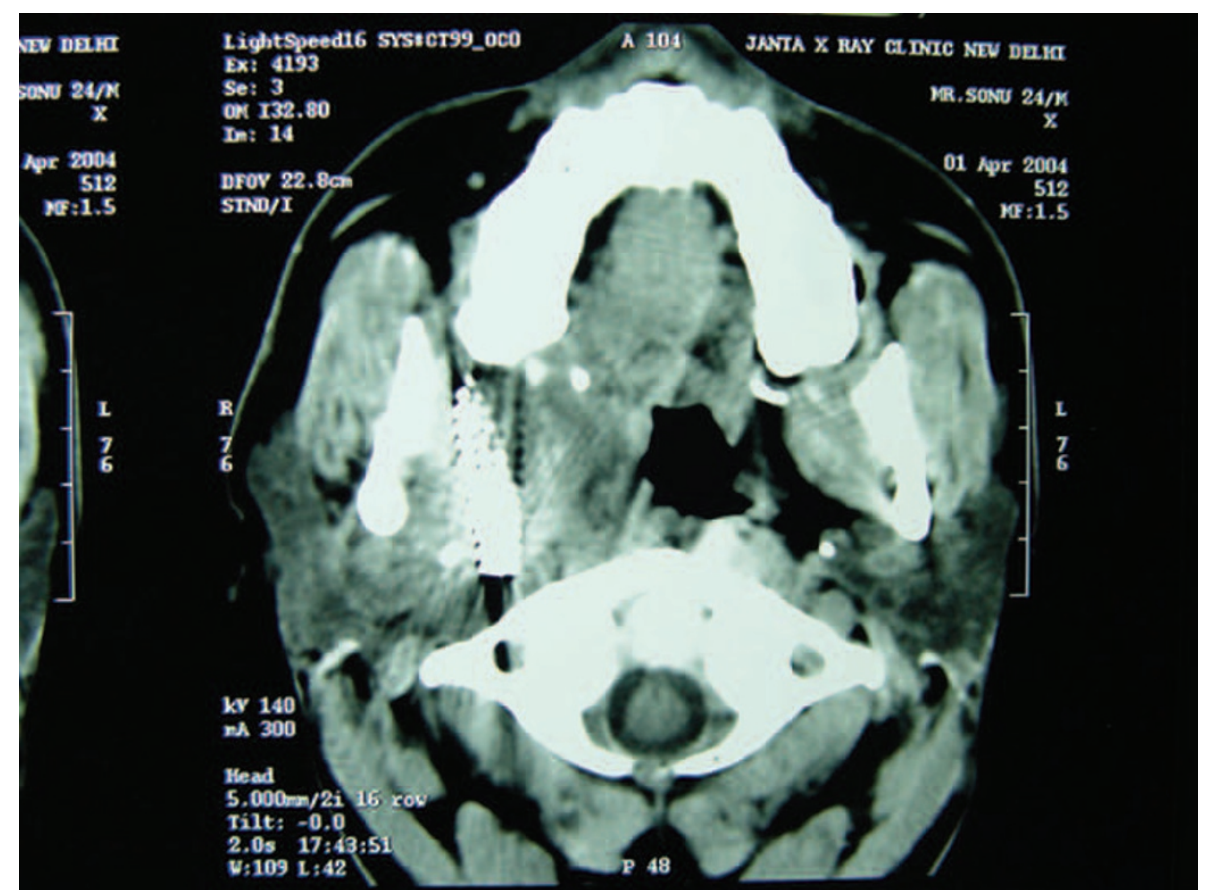

Fig. 3 CT scan

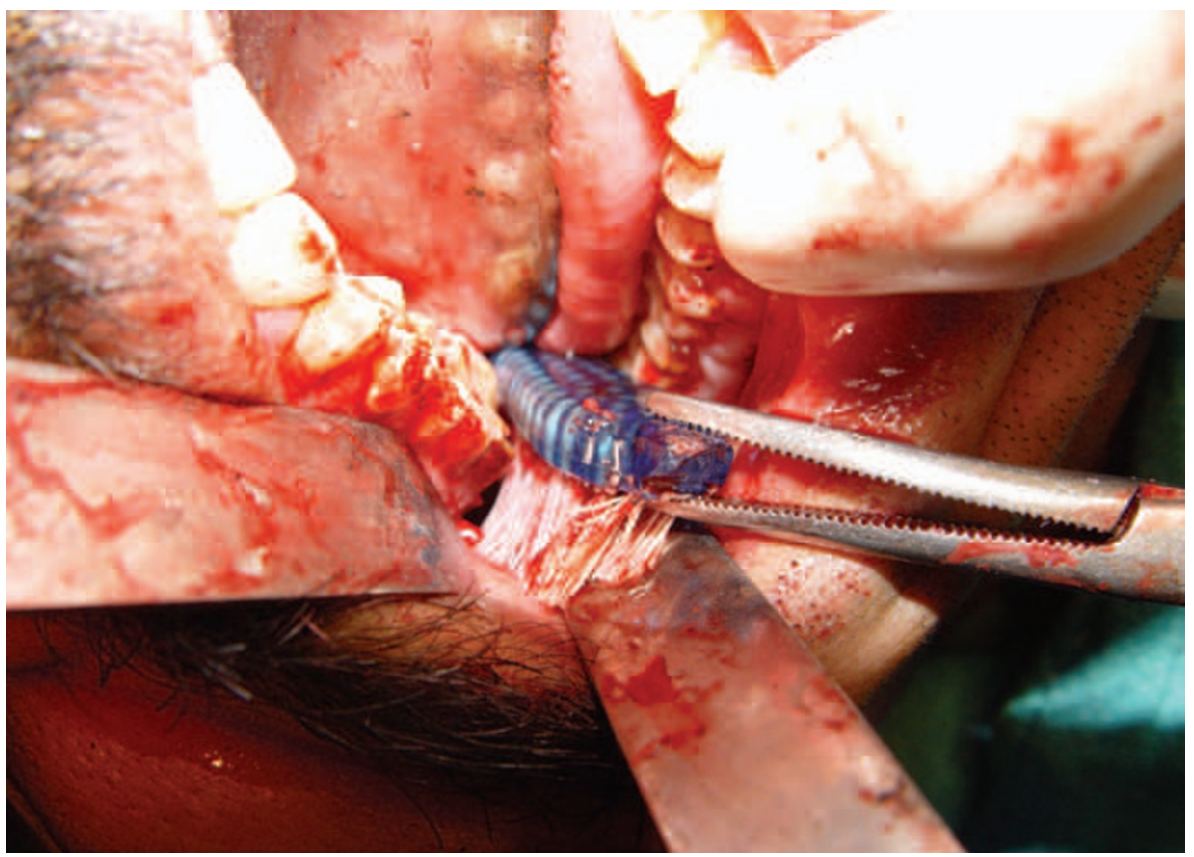

Fig. 4 Surgical retrieval of head of toothbrush

through the wound and the mouth opening was $38 \mathrm{~mm}$.

\section{REVIEW OF LITERATURE}

Foreign body injuries to the soft palate and oropharynx are common in preschool children because of their propensity to fall easily while carrying objects in their mouth. ${ }^{2}$ Even so severe OPT trauma caused by a toothbrush is infrequently reported. We carried out a literature search and found only 11 articles reporting 15 cases over the last 20 years. Table 1 summarises the avail- able information reported in 13 of these cases. Kosaki et al. give details of only two of their four cases who sustained penetrating injury to the oropharynx by a toothbrush. ${ }^{3}$

All cases were reported in children, the oldest of whom was 12 years. Nine of the 13 cases were in children two years or younger. Eight were females and five were male children and almost all had sustained the injury as a result of a fall with their toothbrush in their mouth. In one case, the injury was caused by a cricket ball hitting the cheek while the 
Table 1 Cases of oropharyngeal trauma (OPT) caused by a toothbrush

\begin{tabular}{|c|c|c|c|c|c|}
\hline Authors & Year & Age/Sex & Type of Injury & Site of Injury & Complications \\
\hline Shirali G N et al. & 1988 & 5 years $/ F$ & Impalement & Lt peritonsillar area & Nil \\
\hline Kosaki H et al. & 1992 & $\begin{array}{l}12 \mathrm{mth} / \mathrm{F} \\
2 \text { years } / \mathrm{F}\end{array}$ & $\begin{array}{l}\text { Penetrating } \\
\text { Penetrating }\end{array}$ & $\begin{array}{l}\text { Lt tonsillar fossa } \\
\text { Rt tonsillar fossa }\end{array}$ & $\begin{array}{l}\text { Subcutaneous and retropharyngeal } \\
\text { emphysema/abscess mediastinitis } \\
\text { Retropharyngeal emphysema/abscess }\end{array}$ \\
\hline Sidhu M K et al. & 1996 & $17 \mathrm{mth} / \mathrm{M}$ & Blunt Injury & Rt soft palate & $\begin{array}{l}\text { Carotid artery dissection and thrombosis } \\
\text { causing neurological sequelae }\end{array}$ \\
\hline Moriarty K P et al. & 1997 & 2 year $/ F$ & Blunt injury & Pharynx & $\begin{array}{l}\text { Internal carotid artery occlusion } \\
\text { and cerebral infarction }\end{array}$ \\
\hline Law R C et al. & 1997 & $\begin{array}{l}13 \mathrm{mth} / \mathrm{F} \\
2 \mathrm{yr} / \mathrm{F}\end{array}$ & $\begin{array}{l}\text { Penetrating } \\
\text { Penetrating }\end{array}$ & $\begin{array}{l}\text { Rt anterior faucial pillar } \\
\text { Lt pyriform fossa }\end{array}$ & $\begin{array}{l}\text { Cervical emphysema/ } \\
\text { pneumomediastinum/pneumothorax } \\
\text { Cervical emphysema/upper lobe collapse }\end{array}$ \\
\hline Tsukuda T et al. & 2000 & $16 \mathrm{mths} / \mathrm{F}$ & Embedded for 2 months & $\begin{array}{l}\text { Back wall of Mesopharynx/ } \\
\text { hypopharynx }\end{array}$ & $\begin{array}{l}\text { Upper airway inflammation } \\
\text { and stridor and fever }\end{array}$ \\
\hline Jacob J E. & 2001 & $5 \mathrm{yr} / \mathrm{M}$ & Embedded for 18 months & Rt Upper cervical soft tissues & $\begin{array}{l}\text { Neck Abscess cavity with } \\
\text { external swelling }\end{array}$ \\
\hline Tanaka T et al. & 2002 & $12 \mathrm{mths} / \mathrm{M}$ & $\begin{array}{l}\text { Embedded } \\
\text { (managed immediately) }\end{array}$ & $\begin{array}{l}\text { Lt Retropharyngeal space } \\
\text { beside the carotid artery }\end{array}$ & Nil \\
\hline Oza N et al. & 2002 & 12 year $/ \mathrm{M}$ & Embedded for $24 \mathrm{hrs}$ & Rt Pterygomandibular space & Trismus \\
\hline Burduk P K & 2006 & $18 \mathrm{mths} / \mathrm{M}$ & $\begin{array}{l}\text { Embedded } \\
\text { (managed immediately) }\end{array}$ & Rt Parapharyngeal space & Nil \\
\hline Sasaki T et al. & 2006 & $10 \mathrm{yr} / \mathrm{F}$ & $\begin{array}{l}\text { Embedded } \\
\text { (managed immediately) }\end{array}$ & Rt parapharyngeal space & $\begin{array}{l}\text { Emphysema from level of } \\
\text { penetration to mediastinum }\end{array}$ \\
\hline
\end{tabular}

child was brushing his teeth outdoors. ${ }^{4}$ In yet another case the injury was caused when the child fainted while her mother was brushing her teeth. ${ }^{5}$ The sudden weight of her body forced the toothbrush into the oropharynx.

OPT caused by a toothbrush may be classified as follows:

Blunt injury: where there is no mucosal break or perforation. Two among the reported cases had life-threatening complications related to blunt injury to the soft palate and pharyn $x^{6,7}$

Penetrating injury: where there is deep laceration/perforation of the soft tissues but the toothbrush has already been extricated from the wound at the time of presentation to the hospital. Four cases of deep laceration of the tonsillar area with subsequent problems have been reported ${ }^{3,8}$

Impalement injury: where the toothbrush is impacted within the soft tissues because of 'fish-hooking' of the bristles. Shirali et al. have reported a case of toothbrush impalement in the peritonsillar area in a 5-year-old child ${ }^{9}$
Embedded: when the head of the toothbrush breaks and is retained deep within the tissues. Six cases of an embedded head of the toothbrush medial to the ramus of the mandible have been published., ${ }^{4,5}, 10-13$ These injuries can be missed at the initial examination and may report later with complications. One reported case had the embedded head of the toothbrush in his oropharynx for 18 months before it was removed..$^{11}$ Tomoko et al. published a case where the patient reported two months after injury with stridor and fever. ${ }^{10}$ Another case reported after 24 hours for treatment of trismus which developed after trauma. ${ }^{4}$ In three remaining patients the toothbrush head was retrieved surgically without delay and no major complications were encountered..$^{5,12,13}$

In our survey, the pharyngeal wall was most frequently traumatised causing violation of the parapharyngeal or retropharygeal spaces. ${ }^{5,7,10-13}$ The tonsillar and peritonsillar area was injured less frequently. ${ }^{3,8,9}$ The soft palate was reported to be the site of blunt trauma by Sidhu et al. ${ }^{6}$ while the pterygomandibular space was perforated in the case reported by Oza et al. ${ }^{4}$

Oropharyngeal trauma, irrespective of the type of injury, can lead to lifethreatening complications. Nine of the cases reviewed here developed serious problems related to the injury. Cervical and retropharyngeal emphysema and neck abscesses progressing to pneumomediastinum and mediastinitis occurred most frequently. $3,5,8,10,11$ Internal carotid artery thrombosis with neurological sequelae occurred in two patients. ${ }^{6,7}$ No deaths were reported by any of the authors.

\section{DISCUSSION}

The proposed system of classification categorises toothbrush induced injuries according to the clinical presentation alone. This enables subtle differentiation between injuries caused by similar mechanism to an anatomically distinct area. Earlier reports when classified in this manner can be compared more meaningfully. It does not, 
however, imply that one type of injury may be more severe than the other or that complications may be associated more with a particular category of injury.

Blunt injuries to the oro-pharynx are often ignored because of lack of dramatic clinical features. However, even these innocuous looking injuries have been reported to cause internal carotid artery dissection and thrombosis leading to cerebral infarction and neurological complications. The mechanism of injury is thought to be sudden compression of the artery between the intraoral foreign body and the transverse processes of the upper cervical spine. Stretching and shearing of the intima causes dissection and subsequent thrombosis. ${ }^{6}$ The patient may present with neurological symptoms eg hemiparesis, hemiplegia or coma immediately or after a lucid interval of 3-18 hours after injury. It is therefore recommended that any patient with a lateral palate or peritonsillar wound should be admitted and observed for at least 48 hours. $^{14}$ Management includes prompt diagnosis, anticoagulation and carotid artery exploration in selected cases. ${ }^{7}$

All the other categories of OPT are accompanied by a laceration in the oropharynx. If the suspected device which has caused the injury is not available for examination, it is mandatory to get a CT, preferably with 3D reconstruction, so as not to miss an embedded piece deep in the tissues. These injuries, in addition to ICA involvement, run a high risk of air entering the deep neck spaces causing widespread emphysema within the neck, mediastinal emphysema or even pneumoencephalocoele. ${ }^{3}$ Management may require prolonged intubation and mechanically assisted ventilation until the risk of mediastinal infection diminishes. ${ }^{5}$ Deep neck abscess in the lateral or retropharyngeal spaces with the potential to cause mediastinitis must be suspected if the patient has fever, neck stiffness, stridor or sore throat following injury. ${ }^{12}$ Accurate diagnosis can be made with $\mathrm{x}$-rays of the lateral neck which may show widening of the prevertebral or retropharyngeal space. Treatment consists of antibiotic therapy and surgical drainage.
If the CT scan reveals the toothbrush head to be in close proximity to the carotid artery, simple removal may be dangerous as it can cause fatal bleeding. An angiography or magnetic resonance angiography (MRA) may be useful to rule out penetration of the artery. Wide exposure and careful dissection of the bristles under GA will be required in such cases with provision for immediate repair or ligation of the artery to control bleeding during retrieval of the foreign body. ${ }^{5,15}$

Local management of the wound depends on the type of injury. If a deep laceration exists it can be irrigated with an antiseptic solution and the wound simply closed under anaesthesia. When a toothbrush has impacted itself in the oropharyngeal tissues then it may be carefully retrieved under anaesthesia and the wound debrided and closed. However, when the head of the toothbrush is embedded, it can be extracted either intra-orally or extra-orally depending on the proximity to the surface. Amongst the six cases reported, two were retrieved externally. ${ }^{11,13}$ When a deep neck abscess is suspected, the wound should be left to drain. ${ }^{5,8}$

The case described here was unusual in that the injury was sustained by a 35-year-old male patient during an epileptic attack. Recently, D'Souza et al. have suggested that toothbrushing can induce epileptic attacks in patients with structural lesions in the primary somatosensory area. ${ }^{16}$ They reported on three patients in whom seizure generation occurred as a result of stimulation of the oral somatosensory pathways by toothbrushing. Toothbrushing involves a persistent rhythmic oral sensory stimulus which is likely to evoke the necessary neuronal synchronisation to induce seizures. Seizures then propagate to the adjacent motor cortex through a direct transcortical pathway. Although we did not investigate our patient as to the site of the lesion, it is possible that the seizure was brought about by a similar mechanism. Sudden loss of consciousness in non-epileptics could occur as a result of vagal stimulation by toothbrush movement (vagal syncope). ${ }^{5}$

It has been observed by several authors that these injuries do not bleed profusely in spite of the considerable force required to penetrate the oropharyngeal area. This may be because of the contraction of the pharyngeal muscles around the site of penetration. Broken off toothbrush heads embedded deep within the tissues are therefore missed at the initial examination unless there are witnesses to the injury. In the case reported, neither the patient nor his family realised that the head of the toothbrush had penetrated the pharyngeal area and was retained within the tissues as a foreign body. He only sought treatment 11 months later for unresolved trismus and pus discharge. Had the patient been a city dweller with easy access to medical facilities, it is possible that the foreign body would have been identified earlier. In spite of persistent infection in the pterygomandibular space, the patient did not develop a deep neck abscess or mediastinitis which could have been life threatening. The abscess remained contained within the pterygomandibular space since it was draining freely continuously and never reached a ‘critical' volume.

\section{CONCLUSION}

Oropharyngeal injuries can have devastating consequences, however trivial they may appear. It is important to examine and investigate such patients with care and keep them under observation for 4872 hours if required. Small children, special needs patients and epileptics should always be supervised when brushing their teeth and parents and caretakers must be made aware of the dangers of trauma to the oropharynx.

It has been suggested that toothbrush manufacturers must place a warning on toothbrush packaging. ${ }^{8}$

1. Hefflin B J, Gross T P, Schroeder T J. Estimates of medical device-associated adverse events from emergency departments. Am J Prev Med 2004; 27: 246-253.

2. Younessi $0 \mathrm{~J}$, Alcaino E A. Impalement injuries of the oral cavity in children: a case report and survey of literature. Int J Paediatr Dent 2007; 17: 66-71.

3. Kosaki H, Nakamura N, Toriyama Y. Penetrating injuries to the oropharynx. J Laryngol Otol 1992; 106: 813-816.

4. Oza N, Agarwal K, Panda K N. An unusual mode of injury-implantation of a broken toothbrush medial to ramus: report of a case. ASDC J Dent Child 2002; 69: 125, 193-195.

5. Sasaki T, Toriumi S, Asakage T et al. The toothbrush: a rare but potentially life-threatening cause of penetrating oropharyngeal trauma in children. 
Pediatrics 2006; 118: e1284-e1286.

6. Sidhu M K, Shaw D W W, Roberts T S. Carotid artery injury and delayed cerebral infarction after minor pharyngeal trauma. AJR Am J Roentgenol 1996; 167: 1056.

7. Moriarty K P, Harris B H, Benitez-Marchand K. Carotid artery thrombosis and stroke after blunt pharyngeal trauma. J Trauma 1997; 42: 541-543.

8. Law R C, Fouque C A, Waddell A, Cusick E. Lesson of the week. Penetrating intra-oral trauma in children. Br Med J 1997; 314: 50-51.

9. Shirali G N, Savant R A, Uppal P K. Toothbrush: an unusual foreign body in ENT practice. J Laryngol Otol 1988; 102: 1068-1069.

10. Tsukuda T, Kudo F. Pharyngeal foreign bodies in infants persisting for 2 months: two case reports. J Otolaryngol Jpn 2000; 106: 24-27.

11. Jacob J E. Letter to the editor. Unusual foreign body in the neck. Indian Pediatr 2001; 38: 798-799.

12. Tanaka T et al. Penetrating injury to the pharynx by a toothbrush in a pediatric patient. Auris Nasus Larynx 2002; 29: 387-389.

13. Burduk P K. Parapharyngeal space foreign body. Eur Arch Otorhinolaryngol 2006; 263: 772-774.
14. Hengerer A S, DeGroot T R, Rivers R J et al. Internal carotid artery thrombosis following soft palate injuries: a case report and review of 16 cases. Laryngoscope 1984; 94: 1571-1575.

15. Ebenezer J, Adhikari D D, Mathew G C, Chacko R K. An unusual injury from a toothbrush a case report. J Indian Soc Pedod Prev Dent 2007; 25 200-202.

16. D'Souza W J, O'Brien T J, Murphy M et al. Toothbrushing-induced epilepsy with structural lesions in the primary somatosensory area. Neurology 2007; 68: 769-771. 